\title{
Fabella Syndrome: A Typical Case of Misdiagnosis and Discussion
}

\author{
Mohammed H. Karrar Alsharif 1,2,3*, Juman M. Almasaad ${ }^{2,4}$, Nagi M. Bakhit ${ }^{2,4}$, \\ Khalid M. Taha',6, Mohammed I. Eltahir ${ }^{2,3,7}$, Mamoun A. Alfaki ${ }^{1,3}$, \\ Abubaker Y. Elamin ${ }^{2,3}$, Mohammed A. Noureddin ${ }^{8}$
}

\author{
${ }^{1}$ Department of Basic Medical Science, College of Medicine, Prince Sattam Bin Abdulaziz University, Al Kharj, KSA \\ ${ }^{2}$ Department of Histology \& Embryology, Medical Faculty, Ondukuz Mayis University, Samsun, Turkey \\ ${ }^{3}$ Department of Anatomy, Faculty of Medicine, National University, Khartoum, Sudan \\ ${ }^{4}$ College of Medicine, King Saud Bin Abdulaziz for Health Sciences University, Jeddah, KSA \\ ${ }^{5}$ Department of Anatomy, Faculty of Medicine, El Deain University, El Deain, Sudan \\ ${ }^{6}$ Department of Anatomy, Faculty of Medicine, University of Science and Technology, Khartoum, Sudan \\ ${ }^{7}$ Department of Anatomy, Faculty of Medicine, University of Bahri, Khartoum, Sudan \\ ${ }^{8}$ Department of Medicine, College of Medicine, Prince Sattam Bin Abdulaziz University, Al Kharj, KSA \\ Email:^dr.anatomy83@yahoo.com
}

How to cite this paper: Alsharif, M.H.K., Almasaad, J.M., Bakhit, N.M., Taha, K.M., Eltahir, M.I., Alfaki, M.A., Elamin, A.Y. and Noureddin, M.A. (2019) Fabella Syndrome: A Typical Case of Misdiagnosis and Discussion. Case Reports in Clinical Medicine, 8, 258-273.

https://doi.org/10.4236/crcm.2019.89032

Received: August 27, 2019

Accepted: September 24, 2019

Published: September 27, 2019

Copyright () 2019 by author(s) and Scientific Research Publishing Inc. This work is licensed under the Creative Commons Attribution International License (CC BY 4.0).

http://creativecommons.org/licenses/by/4.0/

c) (i) Open Access

\begin{abstract}
Background: Fabella is a natural occurring sesamoid bone, cartilage or a mixture of both that is usually located at the posterolateral corner (PLC) of the knee [1]. Recently the PLC of the knee has been extensively investigated because it is a common site of injuries and diseases [2] [3]. The complexity of PLC anatomy needs to be fully understood because the fabella could be missed diagnosis as an osteochondral defect, osteochondritis dissecans (OCD), calcific tendinitis, or foreign body. We present a case report of fabella syndrome triggered by trauma and also performed a review of literature for the various diagnoses that might be confused with fabella syndrome. Case presentation: A 29-year-old, Sudanese male presented to the trauma center in King Khalid Hospital in KSA, complaining of pain and partial swelling in his left knee joint due to trauma. Fabella was detected in the posterior lateral corner (PLC) of the knee joint embedded in the lateral head of the gastrocnemius muscle. All other pathological conditions were excluded. Conclusion: Fabella is sesamoid bone with variable size, found in the PLC. Commonly if present it causes periodic pain especially in the fully extended knee or it remains asymptomatic. Trauma, surgery, sports or heavy extreme activities may trigger the pain of asymptomatic fabella. Clinicians should consider that pain in the PLC of the knee can result from the presence of the fabella in a condition called fabella syndrome.
\end{abstract}




\section{Keywords}

Fabella Syndrome, Sesamoid Bone, Osteochondral Defect, Osteochondritis Dissecans, Calcific Tendinitis, Foreign Body

\section{Introduction}

Among the human body joints, the knee is the largest most, superficial and complicated joint. It takes place between the condyles of the femur proximally and the tibial plateau distally. It has been classified as a hinge type of synovial joint allowing flexion and extension; even so, the gliding, rolling and with rotation about a vertical axis movements are possible with little degrees [4]. The stability factors of knee joint are composed of 28 unique static and dynamic stabilizers (ligaments, tendons, meniscal structures, and strong muscles) [5] [6]. Recently the posterior-lateral corner (PLC) of the knee has been commonly investigated because of its importance in knee stability and considered as a common side of injuries and diseases [2] [3]. The complexity of PCL anatomy needs to fully understand because it can contribute to the misdiagnosis for orthopedic surgeons [4] [7]. The static components of PLC are the fibular collateral, fabellofibular and popliteofibular ligaments, and posterolateral capsule, whereas the dynamic components are the tendons of the popliteus, biceps femoris, lateral head of gastrocnemius and iliotibial tract; that together provide lateral knee stability [8].

PLC is a common side of injuries and abnormal condition such as fabella syndrome, osteochondral defect, osteochondritis dissecans, calcific tendinitis, and foreign body. All of these conditions will be reviewed briefly in this study.

The current study aimed as well to report an unfamiliar morphology of posterior lateral corner of the knee (fabella syndrome) and its differential diagnosis in order to avoid misdiagnosis in such case.

\section{Case Report}

A 29-year-old, Sudanese male presented to the trauma center in King Khalid Hospital in KSA, complain from pain and partial swelling in his left knee joint due to falling down trauma.

Physical examination of the patient showed a partial swelling with normal popliteal fossa. On palpation temperature was normal in the region and there was no tenderness around the knee joint. A general screen of the patient's gait revealed no significant abnormalities. Changing position from sitting to standing and tolerance to either position was painless. The patient was asked if he has any similar symptoms before the trauma and the answer was no. Instability tests showed negative results and there were no abnormalities upon examination of distal neurovascular status.

Although he visited two physicians during this time, the problem still re- 
mained due to misdiagnoses.

Eventually in the hospital, after a precise examination, X-ray showed a fabella in close topographical relation to the posterior lateral femoral condyle embedded in the lateral head of gastrocnemius muscle (Figure 1). This result was confirmed by MRI findings as seen in Figure 2.
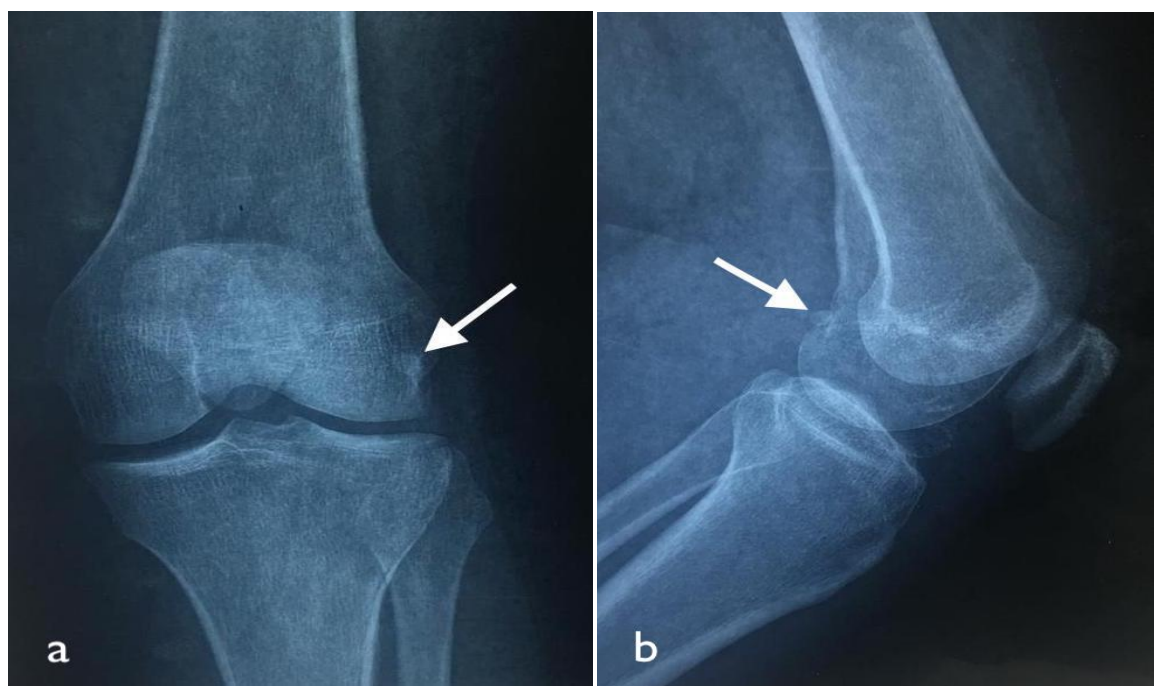

Figure 1. (a) Anteroposterior (AP), (b) Lateral view of plane radiograph showing fabella (arrows) located on the dorsal aspect of the lateral femural condyle.

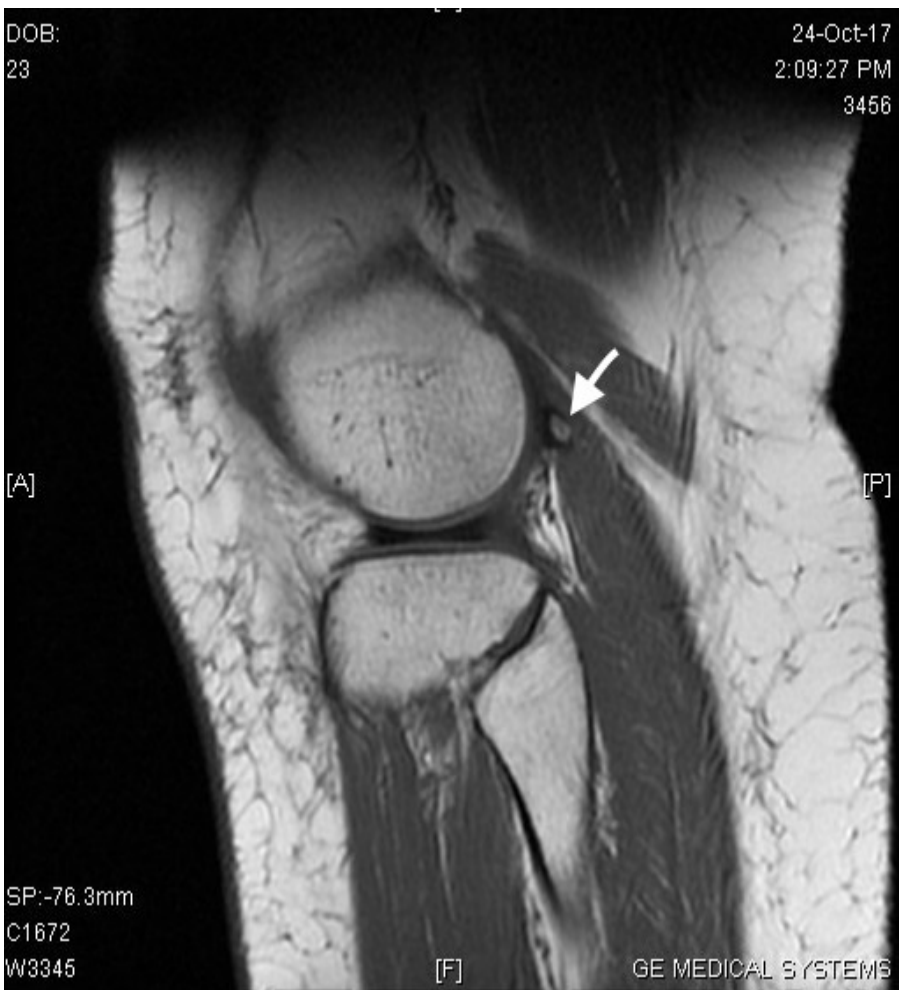

Figure 2. MRI showing: a sagittal plane of knee joint at the lateral condyle of the femur. Arrow indicates the fabella associated with lateral head of gastrocnemius muscle. 


\section{Discussion}

Flabella is a small sesamoid bone found commonly in the lateral head of gastrocnemius muscle [1], but few studies reported that it can be found in the medial head [9] [10]. It is believed that the fabella is associated with the distal part of the short head of biceps femoris tendon [11] [12]. Also, it had been reported in the knee of the dogs, cats, and rabbits [13] [14].

Researchers were varied about the time of development of the fabella. Some authors noticed that it appeared at the age of 10 years and remains unossified until the age of $12-15$ [15]. And some of them reported that it first appeared in the second trimester around $15^{\text {th }}$ week of gestation [16]. fabella was developed when the plantaris and lateral head of gastrocnemius were entirely separated, but not when both muscles converge to a single belly [17]. The presence of fabella is widely variable. Table 1 demonstrates the prevalence of fabella on the previous studies including different ethnic groups [18].

Fabella could be pure osseous, cartilaginous or mixed in nature, forming its own joint with lateral condyle of the femur posteriorly [18] [19]. It has a variable size ranging from a very small dot with a $2.2 \mathrm{~mm}$ in diameter [19] [20] to large size measured $15 \times 8 \times 9 \mathrm{~mm}$ [21] $13 \mathrm{~mm} \times 10 \mathrm{~mm}$ [22]. It's larger in male than the female, which supports the theory of biomechanical role of fabella [11] [12]. Authors believe that the fabella is involved in the stability of the posterolateral aspect of the knee [23].

The functions of sesamoid are to protect the tendon of muscle from being damaged by friction, change the direction of the puling muscles and helping muscles in action [24]. During the transition from the quadrupedal posture to the bipedal, the fabella seemly starts to disappear, because the standing position in bipedal need more stability and less rotation [25] [26] so that the fabella variable absent and it classified as retrogressive anatomical that lost it function with an upright position in human.

Table 1. Prevalence of the fabella in the different ethnic groups.

$\begin{array}{cccc}\text { Author } & \text { Year } & \text { Prevalence } \% & \text { Ethnic group } \\ \text { Yu } \text { et al. } & 1996 & 19.0 & \text { Caucasian American } \\ \text { Sarin } \text { et al. } & 1999 & 31.3 & \text { Caucasian America } \\ \text { Raheem } \text { et } \text { al. } & 2007 & 9.1 & \text { Caucasian Irish } \\ \text { Tim } \text { et al. } & 2010 & 3.1 & \text { Caucasian Brazilian } \\ \text { Phukubye and Oyedele } & 2011 & 23.5 & \text { Caucasian and African } \\ \text { Piyawinijwong } \text { et al. } & 2012 & 50.5 & \text { Asian Thailand } \\ \text { Tabira } \text { et } \text { al. } & 2012 & 68.6 & \text { Asian Japanese } \\ \text { Zeng } \text { et } \text { al. } & 2012 & 86.9 & \text { Asian Chinese } \\ \text { Chew } \text { et } \text { al. } & 2014 & 31.25 & \text { Asian, Singapore } \\ \text { O.F. Egerci } \text { et } \text { al } & 2016 & 22.8 & \text { Caucasian Turkish }\end{array}$


Asymptomatic fabella remains silence until it has been detected by accident in routine lateral knee radiograph. And this was accepted as normal anatomy without any complain pathology in knee that may confuse radiologist with other pathological conditions [27] [28] like osteophytes in osteoarthritis or intrameniscal calcifications.

\subsection{Fabella Syndrome}

Fabella Syndrome describes traditionally posterolateral knee pain, occurring due to biomechanical pressure of the fabella against the lateral femoral condyle. Given its rarity, its diagnosis is often overlooked [29]. Fabella leads to many pathological conditions such as fabella syndrome and common fibular nerve palsy [30]. Also the presence of the fabella increases risk of osteoarthritis in the knee joint [31]. Due to its close anatomical association, authors believe that it may cause compression of popliteal artery [30] [32] or peroneal nerve at PLC of the knee [33] [34].

Pain at the posterior lateral part of the knee; which is augmented by full joint extension, is defined as fabella syndrome [35]. Authors referred this painful syndrome as the osteoarthritis [24] [36], degenerative arthritis and various deformity [37], dislocations [38], fracture [39] [40], and chondromalacia of the fabella [1] [28].

Absence of the fabella is a normal anatomical variation, clinicians and radiologist should know about the morphological features, position, and incidence of this bone. The fabella detected by different modalities of radiography such as $\mathrm{X}$-ray, US, and MRI or by the cadaveric dissection.

\subsection{Osteochondral Defect}

Osteochondral defect is a common serious problem from which a large number of people around the world suffer [41]. About $63 \%$ of knees had been associated with chondral damage when investigated by means of arthroscopy, the full-thickness chondral lesion had been found in about $5 \%$ of cases [42]. The chondral lesion is the most common musculoskeletal defect that usually affects old age individuals [43]. Damage affecting chondral and bony part of the joint is called osteochondral defect, when solely articular cartilage is affected the term chondral injury or defect is usually applied [44] [45]. Articular cartilage damage may found isolated, but associated tissues are always involved [46]. Severity and progression of an osteochondral defect are largely affected by many factors such as weight, age, physical activity and genetic background of the individual [41] articular cartilage is avascular therefore it is the capability for regeneration are confined [47] [48]. Hyaline cartilage replaced by fibrocartilage as the joint subject to osteochondral defect, this change leads to joint's deformation and immobility [49]. Osteochondral and even chondral damage can develop into osteoarthritis [50]. Osteoarthritis is a common complication of traumatic injuries that causes joint defects and disabilities [51]. According to the clinical findings joint injuries commonly in- 
volve articular cartilage, supporting tissues and capsule which cause joint degeneration [51]. Chondromalacia, chondral and osteochondral fractures, chondrosis, chondral flaps and osteochondritis dissecans are types of articular cartilage lesion [52].

Data revealed that trauma is the most common cause of the articular cartilage damage and osteochondral deformities [53] [54]. The traumatic lesion is due to either direct stroke or contortion. Ligaments laceration is usually associated with traumatic injuries [52]. Etiology of the osteochondral lesions is also due to other causes rather than trauma such as metabolic defects, ischemia, joint degenerative disease, thromboembolism, corticosteroids or inflammatory diseases [45] [54].

Ankle and knee are the common joints that prone to the osteochondral injuries. Knee is the most frequently affected [44] [54] [55]. Femoral condyles are most common part of the knee impaired by osteochondral lesion and almost $58 \%$ of cases affect the medial femoral condyles [56]. In the ankle the talar dome is the frequent site of lesion [54].

Osteochondral injuries are always associated with pain, swelling, joint instability and dysfunction [57] [58] [59] [60]. Joints injuries disturb daily activities and joints immobility is common complication [61].

There are many imaging modalities used to diagnose chondral and osteochondral lesions, plain radiograph, CT, MRI and ultrasonography [59] [62] [63]. Plain radiograph doesn't give a complete image of the lesion [64]. A Plain radiograph is useful to diagnose a fracture, subchondral cyst, osteochondral fragments and displaced osteochondral bodies [59]. To demonstrate articular cartilage surface using computerized tomography arthrography is the best choice, magnetic resonance is imaging technique through which demonstration of all tissue can be achieved (Figure 3) [59]. The US is used for assessment of both chondral and subchondral tissue components [62].
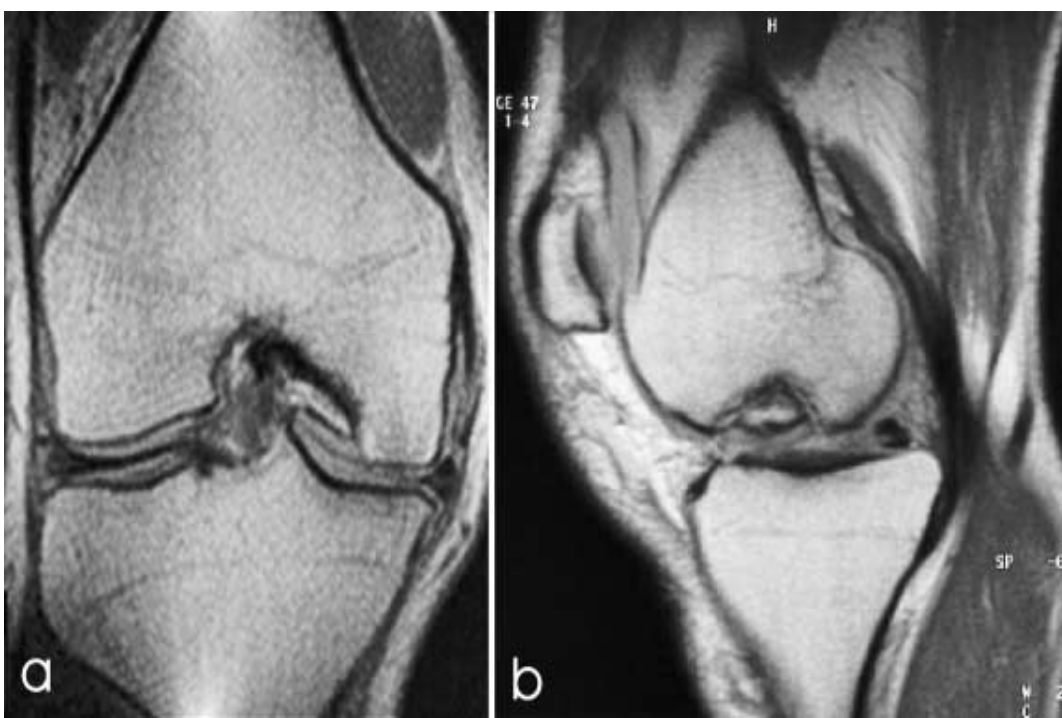

Figure 3. MRI showing: (a) Coronal plane of large osteochondral defect at the medial condyle of the femur; (b) Sagittal plane [65]. 


\subsection{Osteochondritis Dissecans of the Knee}

Osteochondritis dissecans (OCD) is a separation of articular cartilage and underlying bone separate from the specific joint, due to a plane of cleavage through underneath bone (Figure 4 \& Figure 5) [65]. König (1881) was first to describe Osteochondritis dissecans, He thought that a fragment separate as a result of dissecting inflammation followed necrosis caused by trauma [66]. Untreated OCD to the weight bearing bone may develop a degenerative joint disease [67]. According to the skeletal maturity of the patients, OCD is classified into juvenile and adult entities with open and close epiphyseal cartilage plates respectively [68] [69]. Among different joints including wrist, elbow, ankle, and hip, Knee is the commonest site for OCD [70] being engaged to approximately $75 \%$ of the cases, whereas, medial femoral condyle is the primarily affected site having more than $85 \%$ of the cases [67].

The clinical presentation is usually associated with nonspecific symptoms [71], including vague knee pain that is aggravated by certain activity like climbing stairs and may cause activity-related swelling and stiffness. Unstable lesions

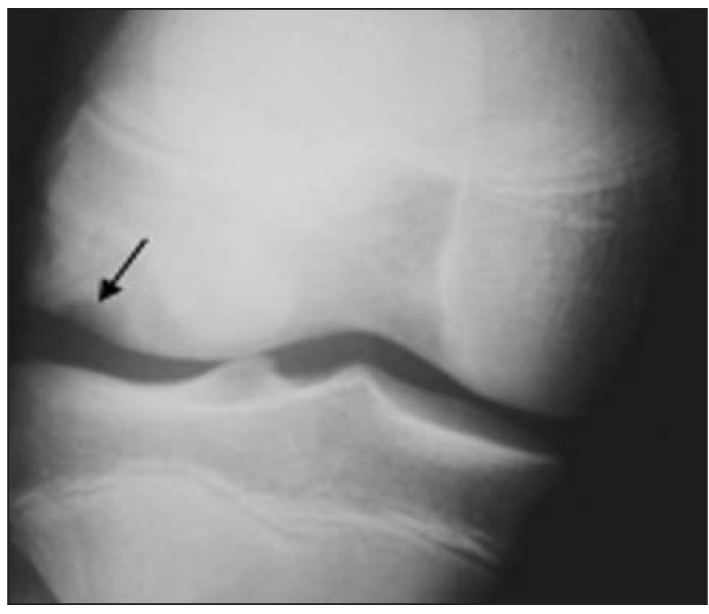

Figure 4. Anteroposterior plane radiograph showing an osteochondritis dissecans lesion [70].
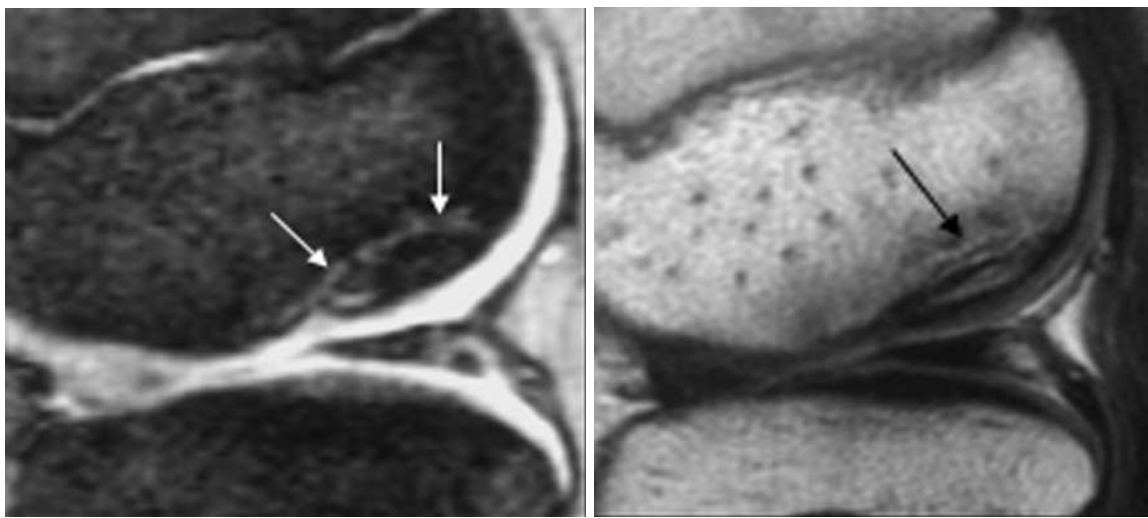

Figure 5. Echo MRI showing a rim of high signal intensity surrounding the osteochondritis dissecans lesion (arrows) [70]. 
usually marked by physical symptoms such as locking or feeling of loose fragment [72] [73]. OCD of the knee is becoming increasingly more frequent in children, adolescent and young adult and is thought to be, due to earlier and increasingly sports endeavors [74] [75]. Despite much speculation, the etiology of OCD remains unclear [76]. A variety of theories have been suggested regarding the cause of OCD, including three main areas; trauma, vascular and genetic [74]. Microscopically, absent of the bone necrosis favour defects in the ossification centers, rather than ischaemia in the distal part of femur [67]. The diagnosis of OCD depends on patient data, physical examination, and radiographic appearance. MRI is considered as the best imaging modality for early detection of lesion [77].

Literature, classified OCD lesions as: grade 1, normal articular cartilage. These asymptomatic lesions and usually found accidentally during another index surgery; grade 2, fragmentation in situ. The overlying cartilage may look normal, but can feel soft to probing and can be indented more easily when compared to the surrounding normal cartilage; grade 3, partial detachment which can cause mechanical symptoms due to micro-motion of the fragment; and grade 4 , is designated to an unstable lesion with complete detachment, loose body present, causing pain and mechanical symptoms [78] [79].

\subsection{Calcific Tendinitis}

Calcific tendinitis is also included in the differential diagnoses of fabella syndrome. In contrast to the posterolateral knee pain experienced in fabella syndrome, calcific tendinitis causes anterior knee pain [80]. It is atypical pain if experienced posterolateral aspect of the knee joint. Calcific tendinitis refers to a painful musculoskeletal disorder characterized by macroscopic calcium deposits in any tendon of rotator cuff [81] [82]. Calcium deposits can be single or multiple and may be found in subacromial bursa. These calcium deposits are composed of a crystalline calcium phosphate called as "hydroxyapatite". It is different from dystrophic calcification, which develops at the edges or at the insertion site of non-viable and poorly vascularized or degenerative tendons. Calcific tendinitis affects $3 \%-20 \%$ of the population; especially the adults whose age is 30 50 years. The most common rotator cuff involved in calcific tendinitis is supraspinatus followed by infraspinatus, teres minor, and subscapularis tendons. Remember, calcific tendinitis can affect any joint, but typically involves shoulder and hip joints. In the knee joint, patellar and quadriceps tendinitis are common [80] [83].

The exact pathogenesis of calcific tendinitis is yet to be revealed. However, recent literature on this condition reported that it is a cell-mediated process with four well-defined phases. These four phases of calcific tendinitis are formative, calcific, resorptive and reparative [84]. In the formative phase of calcific tendinitis, the tendons undergo a fibrocartilaginous transformation. In the calcific phase, calcification of the tendon occurs. Resorptive phase is painful and various 
inflammatory reactions take place within the calcium deposits. In the last phase of calcific tendinitis, fibroblasts restore the normal texture of tendons. In contrast, other authors suggest that matrix vesicles and degeneration of tendons are responsible for calcific tendinitis [85].

Calcific tendinitis may be asymptomatic in one-third of the patients. In others, it is painful, accounting for $7 \%$ of patients with shoulder pain, especially when inflammatory processes are undergoing in the calcium deposits. Osseous changes and calcium deposits can be visualized well with regional radiographs, $\mathrm{CT}$ and MRI. The size of calcium deposits may range from millimeters to centimeters. Remember that an aggressive appearance on imaging films may confuse calcific tendinitis with infection or other diagnoses such as malignancies [86]. CT scan is the best modality to identify subtle osseous changes.

\subsection{Foreign Body}

Foreign body is referred to the substance or object that does not belong to the place where it is found [87]. Fabella might be taken as a foreign body in the knee joint. However, foreign body and fabella syndrome can be differentiated from each other by the shape and density of the object and also by the trauma history. History of trauma and wound of entry favors foreign body in the knee joint while bone-like density and advocates for sesamoid bone. In context with fabella syndrome, Driessen et al. [35] have demonstrated that foreign body can produce pain in the PLC of the knee joint. Foreign bodies in knee joints are rare. Authors reported an intraosseous metallic foreign body in the lateral [88] and medial [89] condyles of the femur associated with pain in the left knee. Low radiopaque objects are usually missed on imaging investigations. Therefore, accurate diagnostic protocol is required to detect these objects in order to avoid any pathological changes and complications. Thorns, wood, and sand are common foreign bodies get into the body during routine accidents.

Radiography is the first investigation performed in detection of any foreign body. However, the disadvantage of radiography is that it is unable to provide exact size of foreign body as it is a 2-dimensional imaging modality. Therefore, further investigation using ultrasonography, CT scan and MR imaging are required to determine the exact size of the foreign body [90]. Determination of size of foreign body and more details are necessary to plan a therapeutic intervention. High frequency US is a safe, cheap and useful imaging modality to detect radiolucent foreign bodies such as wood and sand objects [91]. MRI is not considered a primary imaging modality for the detection of unknown foreign bodies as it is expensive and not easily available everywhere. Additionally, it is difficult to visualize foreign bodies of plastic, iron, glass and sand due to artefacts related to body's composition, which may be encountered on MRI scan.

\section{Conclusions}

Fabella is a normal anatomical variant that may appear in PLC of the knee. It is 
often miss diagnosed in radiography [28]. Moreover, its variable size and nature (bone, cartilage, or mixed) [18] [19] may lead to confusion in the diagnosis of fabella syndrome with the following: 1) Osteochondral defect when it appears like isolated cartilage. 2) Osteochondritis dissecans which, if it is mixed, appears like a fragment of cartilage with underlying bone. 3) Calcific tendinitis when calcium deposit and osseous changes occur. 4) Foreign body especially after wounds injury.

In general, all these conditions can be differentiated from fabella syndrome by taking proper patient history, focusing on the nature (type and site of the pain) and the history of trauma. Also, taking into consideration the size, density, shape, condition of the associated structures would assist in the diagnosis.

Many reports pointed to the presence of the fabella, even though it is not described in most of the anatomy books. The exact role of the fabella in the knee joint and the consequence of its presence remain unclear and need to be clarified with further studies. We recommend giving more attention to this anomaly and the way it may affect the patient's life style.

\section{Conflicts of Interest}

The authors declare no conflicts of interest regarding the publication of this paper.

\section{References}

[1] Ilbrink, S., Kokshoorn, A.P.J., van Loon, C.J.M. and Habets, B. (2013) Het Fabella Syndroom. Sport \& Geneeskunde, No. 3, 20-24.

[2] Bonasia, D.E., et al. (2012) The Posterolateral Corner of the Knee Anatomy. Techniques in Knee Surgery, 11, 41-45. https://doi.org/10.1097/BTK.0b013e3182485d9b

[3] Agha, M. (2017) MRI of the Posterolateral Corner of the Knee, Please Have a Look. Alexandria Journal of Medicine, 53, 261-270. https://doi.org/10.1016/j.ajme.2016.09.002

[4] Moore, K.L., Dalley, A.F. and Agur, A.M. (2013) Clinically Oriented Anatomy. Lippincott Williams \& Wilkins, Philadelphia, PA.

[5] Monk, D. (2013) Examining the Knee Joint. Emergency Nurse, 21, 28-36. https://doi.org/10.7748/en2013.04.21.1.28.e1126

[6] Sanchez, A.R., Sugalski, M.T. and La Prade, R.F. (2006) Anatomy and Biomechanics of the Lateral Side of the Knee. Sports Medicine and Arthroscopy Review, 14, 2-11. https://doi.org/10.1097/00132585-200603000-00002

[7] Cooper, J.M., McAndrews, P.T. and La Prade, R.F. (2006) Posterolateral Corner Injuries of the Knee: Anatomy, Diagnosis, and Treatment. Sports Medicine and Arthroscopy Review, 14, 213-220. https://doi.org/10.1097/01.jsa.0000212324.46430.60

[8] Chun, Y.M., Kim, S.J. and Kim, H.S. (2008) Evaluation of the Mechanical Properties of Posterolateral Structures and Supporting Posterolateral Instability of the Knee. Journal of Orthopaedic Research, 26, 1371-1376. https://doi.org/10.1002/jor.20596

[9] Kaplan, E.B. (1961) The Fabellofibular and Short Lateral Ligaments of the Knee Joint. The Journal of Bone \& Joint Surgery, 43, 169-179.

https://doi.org/10.2106/00004623-196143020-00002 
[10] Kawashima, T., Takeishi, H., Yoshitomi, S., Ito, M. and Sasaki, H. (2007) Anatomical Study of the Fabella, Fabellar Complex and Its Clinical Implications. Surgical and Radiologic Anatomy, 29, 611-616. https://doi.org/10.1007/s00276-007-0259-4

[11] Veltri, D. and Warren, R. (1994) Anatomy, Biomechanics, and Physical Findings in Posterolateral Knee Instability. Clinics in Sports Medicine, 13, 599-614.

[12] Davies, H., Unwin, A. and Aichroth, P. (2004) The Posterolateral Corner of the Knee: Anatomy, Biomechanics and Management of Injuries. Injury, 35, 68-75. https://doi.org/10.1016/S0020-1383(03)00094-9

[13] Bel, L., et al. (2014) Prefemoral Oophorectomy in Red Eared Terrapins (Trachemys Scripta Elegans). Lucrari Stiintifice-Universitatea de Stiinte Agricole a Banatului Timisoara, Timisoara, Romania, 5-9.

[14] Gardell, C. (1980) Miller's Anatomy of the Dog. The Canadian Veterinary Journal, 21, 118. https://doi.org/10.1111/j.1740-8261.1980.tb01673.x

[15] Friedman, A.C. and Naidich, T.P. (1978) The Fabella Sign: Fabella Displacement in Synovial Effusion and Popliteal Fossa Masses: Normal and Abnormal Fabello-Femoral and Fabello-Tibial Distances. Radiology, 127, 113-121.

https://doi.org/10.1148/127.1.113

[16] Nakamura, T., et al. (2010) Human Fetal Anatomy of the Posterior Semimembranosus Complex at the Knee with Special Reference to the Gastrocnemio-Semimembranosus Bursa. The Knee, 18, 271-277. https://doi.org/10.1016/j.knee.2010.05.010

[17] Jin, Z., et al. (2017) A New Insight into the Fabella at Knee: The Foetal Development and Evolution. Folia Morphologica, 76, 87-93.

https://doi.org/10.5603/FM.a2016.0048

[18] Egerci, O.F., et al. (2017) Prevalence and Distribution of the Fabella: A Radiographic Study in Turkish Subjects. Folia Morphologica, 76, 478-483. https://doi.org/10.5603/FM.a2016.0080

[19] Phukubye, P. and Oyedele, O. (2011) The Incidence and Structure of the Fabella in a South African Cadaver Sample. Clinical Anatomy, 24, 84-90. https://doi.org/10.1002/ca.21049

[20] Larson, J.E. and Becker, D.A. (1993) Fabellar Impingement in Total Knee Arthroplasty: A Case Report. The Journal of Arthroplasty, 8, 95-97. https://doi.org/10.1016/S0883-5403(06)80114-2

[21] Hire, J., et al. (2014) Snapping Knee Caused by Symptomatic Fabella in a Native Knee. American Journal of Orthopedics, 43, 377-379.

[22] Dale, K.M., Boggess, S.B., Boggess, B. and Moorman, C.T. (2018) Ultrasound Evaluation and Surgical Excision of a Fabella Causing Peroneal Neuropathy in a Track Athlete. Case Reports in Orthopedics, 2018, Article ID: 2371947. https://doi.org/10.1155/2018/2371947

[23] Flandry, F. and Hommel, G. (2011) Normal Anatomy and Biomechanics of the Knee. Sports Medicine and Arthroscopy Review, 19, 82-92. https://doi.org/10.1097/JSA.0b013e318210c0aa

[24] Sarin, V.K., Erickson, G.M., Giori, N.J., A. Bergman, G. and Carter, D.R. (1999) Coincident Development of Sesamoid Bones and Clues to Their Evolution. The Anatomical Record: An Official Publication of the American Association of Anatomists, 257, 174-180. https://doi.org/10.1002/(SICI)1097-0185(19991015)257:5<174::AID-AR6>3.0.CO;2-O

[25] Seebacher, J., Inglis, A., Marshall, J. and Warren, R. (1982) The Structure of the 
Posterolateral Aspect of the Knee. The Journal of Bone and Joint Surgery, 64, 536-541. https://doi.org/10.2106/00004623-198264040-00008

[26] Chhabra, A., Elliott, C.C. and Miller, M.D. (2001) Normal Anatomy and Biomechanics of the Knee. Sports Medicine and Arthroscopy Review, 9, 166-177. https://doi.org/10.1097/00132585-200107000-00002

[27] Robertson, D.D., et al. (2003) Knee Joint Biomechanics: Relevance to Imaging. In: Seminars in Musculoskeletal Radiology, Thieme Medical Publishers, Inc., New York.

[28] Robertson, A., Jones, S.C.E., Paes, R. and Chakrabarty, G. (2004) The Fabella: A Forgotten Source of Knee Pain? The Knee, 11, 243-245. https://doi.org/10.1016/S0968-0160(03)00103-0

[29] Rankin, I., Rehman, H. and Ashcroft, G.P. (2018) Fabella Syndrome Following De-Rotation Surgery to Correct a Femoral Malunion. The Open Orthopaedics Journal, 12, 346-352. https://doi.org/10.2174/1874325001812010346

[30] Dalip, D., et al. (2018) A Comprehensive Review of the Fabella Bone. Cureus, 10, e2736.

[31] Pritchett, J.W. (1984) The Incidence of Fabellae in Osteoarthrosis of the Knee. The Journal of Bone and Joint Surgery, 66, 1379-1380. https://doi.org/10.2106/00004623-198466090-00009

[32] Ando, Y., et al. (2017) A Case Report on a Very Rare Variant of Popliteal Artery Entrapment Syndrome Due to an Enlarged Fabella Associated with Severe Knee Osteoarthritis. Journal of Orthopaedic Science, 22, 164-168. https://doi.org/10.1016/j.jos.2015.06.025

[33] Takebe, K. and Hirohata, K. (1981) Peroneal Nerve Palsy due to Fabella. Archives of Orthopaedic and Traumatic Surgery, 99, 91-95. https://doi.org/10.1007/BF00389743

[34] Yilmaz, E., et al. (2004) Peroneal Nerve Palsy Due to Rare Reasons: A Report of Three Cases. Acta Orthopaedica et Traumatologica Turcica, 38, 75-78.

[35] Driessen, A., et al. (2014) The Fabella Syndrome-a Rare Cause of Posterolateral Knee Pain: A Review of the Literature and Two Case Reports. BMC Musculoskeletal Disorders, 15, 100. https://doi.org/10.1186/1471-2474-15-100

[36] Ehara, S. (2014) Potentially Symptomatic Fabella: MR Imaging Review. Japanese Journal of Radiology, 32, 1-5. https://doi.org/10.1007/s11604-013-0253-1

[37] Kim, T., Chung, H., Lee, H., Choi, Y. and Son, J.-H. (2018) A Case Report and Literature Review on Fabella Syndrome after High Tibial Osteotomy. Medicine, 97, e9585. https://doi.org/10.1097/MD.0000000000009585

[38] Franceschi, F., et al. (2007) Dislocation of an Enlarged Fabella as Uncommon Cause of Knee Pain: A Case Report. The Knee, 14, 330-332. https://doi.org/10.1016/j.knee.2007.03.007

[39] Heideman, G.M., Baynes, K.E., Mautz, A.P., DuBois, M.S. and Roberts, J.W. (2011) Fabella Fracture with CT Imaging: A Case Report. Emergency Radiology, 18, 357-361. https://doi.org/10.1007/s10140-011-0941-Z

[40] Cherrad, T., Louaste, J., Bousbaä, H., Amhajji, L. and Khaled, R. (2015) Fracture of the Fabella: An Uncommon Injury in Knee. Case Reports in Orthopedics, 2015, Article ID: 396710. https://doi.org/10.1155/2015/396710

[41] Pena, E., Calvo, B., Martínez, M.A. and Doblaré, M. (2007) Effect of the Size and Location of Osteochondral Defects in Degenerative Arthritis. A Finite Element Simulation. Computers in Biology and Medicine, 37, 376-387. 
https://doi.org/10.1016/j.compbiomed.2006.04.004

[42] Chow, J.C., Hantes, M.E., Houle, J.B. and Zalavras, C.G. (2004) Arthroscopic Autogenous Osteochondral Transplantation for Treating Knee Cartilage Defects: A 2-to 5-Year Follow-up Study. Arthroscopy. The Journal of Arthroscopic \& Related Surgery, 20, 681-690. https://doi.org/10.1016/S0749-8063(04)00590-0

[43] Mano, J.F. and Reis, R.L. (2007) Osteochondral Defects: Present Situation and Tissue Engineering Approaches. Journal of Tissue Engineering and Regenerative Medicine, 1, 261-273. https://doi.org/10.1002/term.37

[44] Reilingh, M., Van Bergen, C. and Van Dijk, C. (2009) Diagnosis and Treatment of Osteochondral Defects of the Ankle. SA Orthopaedic Journal, 8, 44-50.

[45] Gormeli, G., Ersoy, Y. and Gormeli, C.A. (2015) Talar Osteochondral Defects. Medicine Science, 4, 2664-2677. https://doi.org/10.5455/medscience.2015.04.8255

[46] Steadman, J.R., et al. (2003) Outcomes of Microfracture for Traumatic Chondral Defects of the Knee: Average 11-Year Follow-up. Arthroscopy: The Journal of Arthroscopic \& Related Surgery, 19, 477-484.

https://doi.org/10.1053/jars.2003.50112

[47] Ho, P.C., Tse, W.-I., Wong, C.W.-Y. and Chow, E.C.-S. (2013) Arthroscopic Osteochondral Grafting for Radiocarpal Joint Defects. Journal of Wrist Surgery, 2, 212-219. https://doi.org/10.1055/s-0033-1351788

[48] Marlovits, S., et al. (2012) Clinical and Radiological Outcomes 5 Years after Matrix-Induced Autologous Chondrocyte Implantation in Patients with Symptomatic, Traumatic Chondral Defects. The American Journal of Sports Medicine, 40, 2273-2280. https://doi.org/10.1177/0363546512457008

[49] Panseri, S., et al. (2012) Osteochondral Tissue Engineering Approaches for Articular Cartilage and Subchondral Bone Regeneration. Knee Surgery, Sports Traumatology, Arthroscopy, 20, 1182-1191. https://doi.org/10.1007/s00167-011-1655-1

[50] Leumann, A., et al. (2011) A Novel Imaging Method for Osteochondral Lesions of the Talus-Comparison of SPECT-CT with MRI. The American Journal of Sports Medicine, 39, 1095-1101. https://doi.org/10.1177/0363546510392709

[51] Buckwalter, J.A. and Brown, T.D. (2004) Joint Injury, Repair, and Remodeling: Roles in Post-Traumatic Osteoarthritis. Clinical Orthopaedics and Related Research, 423, 7-16. https://doi.org/10.1097/01.blo.0000131638.81519.de

[52] Rubin, D.A., Harner, C.D. and Costello, J.M. (2000) Treatable Chondral Injuries in the Knee: Frequency of Associated Focal Subchondral Edema. American Journal of Roentgenology, 174, 1099-1106.

[53] Riyami, M. and Rolf, C. (2009) Evaluation of Microfracture of Traumatic Chondral Injuries to the Knee in Professional Football and Rugby Players. Journal of Orthopaedic Surgery and Research, 4, 13. https://doi.org/10.1186/1749-799X-4-13

[54] Raikin, S.M., et al. (2007) Osteochondral Lesions of the Talus: Localization and Morphologic Data from 424 Patients Using a Novel Anatomical Grid Scheme. Foot \& Ankle International, 28, 154-161. https://doi.org/10.3113/FAI.2007.0154

[55] Schuman, L., Struijs, P.A. and van Dijk, C.N. (2002) Arthroscopic Treatment for Osteochondral Defects of the Talus. Results at Follow-Up at 2 to 11 Years. The Journal of Bone and Joint Surgery. British Volume, 84-B, 364-368. https://doi.org/10.1302/0301-620X.84B3.0840364

[56] Ferrari, M.B., et al. (2017) Osteochondral Allograft Transplantation for Treatment of Focal Patellar Osteochondral Lesion. Arthroscopy Techniques, 6, e907-e912. https://doi.org/10.1016/j.eats.2017.02.025 
[57] Katagiri, H., Mendes, L. and Luyten, F.P. (2017) Definition of a Critical Size Osteochondral Knee Defect and Its Negative Effect on the Surrounding Articular Cartilage in the Rat. Osteoarthritis and Cartilage, 25, 1531-1540. https://doi.org/10.1016/j.joca.2017.05.006

[58] Miyazaki, T., et al. (2002) Dynamic Load at Baseline Can Predict Radiographic Disease Progression in Medial Compartment Knee Osteoarthritis. Annals of the Rheumatic Diseases, 61, 617-622. https://doi.org/10.1136/ard.61.7.617

[59] Linklater, J.M. (2010) Imaging of Talar Dome Chondral and Osteochondral Lesions. Topics in Magnetic Resonance Imaging, 21, 3-13. https://doi.org/10.1097/RMR.0b013e31820ef1c2

[60] Martin, I., Miot, S., Barbero, A., Jakob, M. and Wendt, D. (2007) Osteochondral Tissue Engineering. Journal of Biomechanics, 40, 750-765. https://doi.org/10.1016/j.jbiomech.2006.03.008

[61] Degen, R.M., et al. (2017) Outcomes Following Structural Grafting of Distal Femoral Osteochondral Injuries in Patients Aged 40 Years and Older. Journal of Knee Surgery, 30, 244-251. https://doi.org/10.1055/s-0036-1584534

[62] Penttilä, P., et al. (2015) Diagnosis of Knee Osteochondral Lesions with Ultrasound Imaging. Arthroscopy Techniques, 4, e429-e433.

https://doi.org/10.1016/j.eats.2015.04.002

[63] Engebretsen, L., Arendt, E. and Fritts, H.M. (1993) Osteochondral Lesions and Cruciate Ligament Injuries. MRI in 18 Knees. Acta Orthopaedica Scandinavica, 64, 434-436. https://doi.org/10.3109/17453679308993661

[64] Saxena, A. and Eakin, C. (2007) Articular Talar Injuries in Athletes. The American Journal of Sports Medicine, 35, 1680-1687. https://doi.org/10.1177/0363546507303561

[65] Agneskirchner, J.D., Brucker, P., Burkart, A. and Imhoff, A.B. (2002) Large Osteochondral Defects of the Femoral Condyle: Press-Fit Transplantation of the Posterior Femoral Condyle (MEGA-OATS). Knee Surgery, Sports Traumatology, Arthroscopy, 10, 160-168. https://doi.org/10.1007/s00167-001-0259-6

[66] Green, J. (1966) Osteochondritis Dissecans of the Knee. The Journal of Bone and Joint Surgery. British Volume, 48-B, 82-91. https://doi.org/10.1302/0301-620X.48B1.82

[67] Hanna, S., Aston, W.J., Gikas, P.D. and Briggs, T.W. (2008) Bicondylar Osteochondritis Dissecans in the Knee. Bone \& Joint Journal, 90, 232-235.

[68] Cahill, B.R. (1995) Osteochondritis Dissecans of the Knee: Treatment of Juvenile and Adult Forms. Journal of the American Academy of Orthopaedic Surgeons, 3, 237-247. https://doi.org/10.5435/00124635-199507000-00006

[69] Green, W.T., Banks, H.H. and Banks, H. (1990) Osteochondritis Dissecans in Children. Clinical Orthopaedics and Related Research, 255, 3-12. https://doi.org/10.1097/00003086-199006000-00002

[70] Berná-Serna, J.D., Martinez, F., Reus, M. and Berná-Mestre, J.D. (2008) Osteochondritis Dissecans of the Knee. Journal of Ultrasound in Medicine, 27, 255-259. https://doi.org/10.7863/jum.2008.27.2.255

[71] DellaMaggiora, R., Vaishnav, S. and Vangsness, C.T. (2008) Osteochondritis Dissecans of the Adult Knee. Operative Techniques in Sports Medicine, 16, 65-69. https://doi.org/10.1053/j.otsm.2008.10.012

[72] Owens, J.B. and Lattermann, C. (1991) Management of Osteochondritis Dissecans of the Knee. Arthroscopy, 7, 101-104. 
https://doi.org/10.1016/0749-8063(91)90048-3

[73] Wilson, J. (1967) A Diagnostic Sign in Osteochondritis Dissecans of the Knee. The Journal of Bone \& Joint Surgery, 49, 477-480. https://doi.org/10.2106/00004623-196749030-00006

[74] Kocher, M.S., Tucker, R., Ganley, T.J. and Flynn, J.M. (2006) Management of Osteochondritis Dissecans of the Knee: Current Concepts Review. The American Journal of Sports Medicine, 34, 1181-1191. https://doi.org/10.1177/0363546506290127

[75] Green, D.W., et al. (2016) Retrospective Cohort Study of 207 Cases of Osteochondritis Dissecans of the Knee: Risk Factors and Outcomes Associated with Surgical Treatment. Orthopaedic Journal of Sports Medicine, 4. https://doi.org/10.1177/2325967116S00131

[76] Jones, M. and Williams, A. (2016) Osteochondritis Dissecans of the Knee. The Bone \& Joint Journal, 98, 723-729. https://doi.org/10.1302/0301-620X.98B6.36816

[77] Phillips, M.D. and Pomeranz, S.J. (2008) Imaging of Osteochondritis Dissecans of the Knee. Operative Techniques in Sports Medicine, 16, 52-64.

https://doi.org/10.1053/j.otsm.2008.09.001

[78] Jacobs, J.C., Archibald-Seiffer, N., Grimm, N.L., Carey, J.L. and Shea, K.G. (2014) A Review of Arthroscopic Classification Systems for Osteochondritis Dissecans of the Knee. Clinics in Sports Medicine, 33, 189-197. https://doi.org/10.1016/j.csm.2013.11.005

[79] Nelson, D.W., DiPaola, J., Colville, M. and Schmidgall, J. (1990) Osteochondritis Dissecans of the Talus and Knee: Prospective Comparison of MR and Arthroscopic Classifications. Journal of Computer Assisted Tomography, 14, 804-808. https://doi.org/10.1097/00004728-199009000-00026

[80] Leggit, J.C. (2002) Photo Quiz. Lateral Knee Pain after Aerobic Exercise. American Family Physician, 66, 841-842.

[81] Merolla, G., Singh, S., Paladini, P. and Porcellini, G. (2016) Calcific Tendinitis of the Rotator Cuff: State of the Art in Diagnosis and Treatment. Journal of Orthopaedics and Traumatology, 17, 7-14. https://doi.org/10.1007/s10195-015-0367-6

[82] ElShewy, M.T. (2016) Calcific Tendinitis of the Rotator Cuff. World Journal of Orthopedics, 7, 55-60. https://doi.org/10.5312/wjo.v7.i1.55

[83] Webb, S., Hopper, M. and Chitnavis, J. (2018) Calcific Tendonitis of the Quadriceps Tendon. Journal of Surgical Case Reports, 2018, rjy053. https://doi.org/10.1093/jscr/rjy053

[84] Siegal, D.S., Wu, J.S., Newman, J.S., del Cura, J.L. and Hochman, M.G. (2009) Calcific Tendinitis: A Pictorial Review. Canadian Association of Radiologists Journal, 60, 263-272. https://doi.org/10.1016/j.carj.2009.06.008

[85] Gohr, C.M., Fahey, M. and Rosenthal, A.K. (2007) Calcific Tendonitis: A Model. Connective Tissue Research, 48, 286-291. https://doi.org/10.1080/03008200701692362

[86] Flemming, D.J., et al. (2003) Osseous Involvement in Calcific Tendinitis: A Retrospective Review of 50 Cases. American Journal of Roentgenology, 181, 965-972. https://doi.org/10.2214/ajr.181.4.1810965

[87] Parajuli, R. (2015) Foreign Bodies in the Ear, Nose and Throat: An Experience in a Tertiary Care Hospital in Central Nepal. International Archives of Otorhinolaryngology, 19, 121-123. https://doi.org/10.1055/s-0034-1397336

[88] Reshma, S. (2017) An Unusual Case of Metallic Foreign Body in the Left Knee: A 
Rare Case Report. International Journal of Research in Orthopaedics, 3, 895-897. https://doi.org/10.18203/issn.2455-4510.IntJResOrthop20172893

[89] Helito, C.P., et al. (2014) An Unusual Metallic Foreign Body inside the Knee Medial Femoral Condyle. Case Reports in Orthopedics, 2014, Article ID: 849020. https://doi.org/10.1155/2014/849020

[90] Panigrahi, R., et al. (2015) Foreign Body Detection in Musculoskeletal Injuries: A in Vitro Blinded Study Comparing Sensitivity among Digital Radiography, Ultrasonography, CT and Magnetic Resonance Imaging. Musculoskeletal Regeneration, 1.

[91] Peterson, J.J., Bancroft, L.W. and Kransdorf, M.J. (2002) Wooden Foreign Bodies: Imaging Appearance. American Journal of Roentgenology, 178, 557-562.

https://doi.org/10.2214/ajr.178.3.1780557

\begin{abstract}
Abbreviations
PLC: Posterolateral Corner

OCD: Osteochondritis Dissecans

CT: Computed Tomography
\end{abstract}

MRI: Magmatic Resonance Imaging 